\title{
EL PROCESO DE SUBURBANIZACIÓN DEL CORDÓN OESTE METROPOLITANO DE ROSARIO. IDEAS DE CIUDAD ${ }^{11}$
}

\section{Alejandra M. J. Parussini}

Arquitecta graduada de la Facultad de Arquitectura, Diseño y Urbanismo de la Universidad Nacional de Rosario, año 2007. Estudiante de posgrado en Planificación Urbano-Territorial UNR, año 2008-2010. Adscripta de cátedra (2009-2011) en la materia Teoría y Prácticas Urbanísticas UNR, Titular: Oscar Bragos. Becaria de iniciación en la Investigación Científica CIUNR (2010-2012), proyecto: "Suburbanización, Ideas de ciudad y Políticas Públicas en la conformación del Cordón Oeste Metropolitano de Rosario".

ISNN 1666-6I86. Volumen 12 N 12 (Junio 20I2) pp. II5-I35 - Recibido: 29-08-II Aprobado: 04-04-I2

1- El presente trabajo se basa en el estudio realizado a través de la beca de investigación CIUNR (Centro de Investigaciones de la Universidad $\mathrm{Na}$ cional de Rosario) 2010-2012. Resolución N. ${ }^{\circ} 4067 / 2010$. Dirigida por Oscar Bragos y codirigida por Silvina Pontoni, "Suburbanización, Ideas de ciudad y Políticas urbanas en la conformación del cordón oeste metropolitano de Rosario". 


\section{Resumen}

Las aglomeraciones urbanas actuales han integrado espacial y funcionalmente a las ciudades próximas, mediante un proceso de transformación territorial caracterizado por la expansión urbana dispersa. La suburbanización resulta hoy uno de los principales patrones de desarrollo de las grandes ciudades.

El caso de estudio se presenta como una estribación metropolitana de la ciudad de Rosario, que configura al Cordón Oeste Metropolitano, y ha experimentado un proceso de suburbanización vinculado con las expansiones urbanas de la ciudad central, que comenzó a principios de los años 60 y se intensificó en los años 90. Este cordón ofrece un área de esparcimiento, recreación y descanso debido a sus condiciones naturales y a su gran forestación. Su proceso se concretó mediante sucesivas operaciones inmobiliarias, ventas de loteos de fin de semana o viviendas permanentes y la incorporación de nuevas urbanizaciones de tipo cerrado, en donde se presentan características propias del modelo de ciudad jardín.

Palabras clave

Suburbanización, ideas de ciudad, Cordón Oeste Metropolitano Rosario.

\section{Abstract}

Current conurbations have spatially and functionally swallowed nearby towns, through a process of territorial transformation characterized by urban sprawl. Suburbanization is today one of the main patterns of development of large cities. This case study presents the case of linear sprawl. The West Spur of the metropolitan city of Rosario. This Spur has undergone a process of urban sprawl linked to the central city, which began in the early 60's and intensified in the 90s. The Spur provides a recreation area due to its natural conditions and its substantial forest landscape. The expansion process was shaped through successive property transactions, including sales of building lots for weekend or permanent housing, and the incorporation of new gated community developments which present characteristics of the garden city model.

$\underline{\text { Keywords }}$

Suburbanization, ideas city, Metropolitan West Cord Rosary. 


\section{INTRODUCCIÓN}

La aparición de nuevas tecnologías de la información y la reestructuración económica, que se inició a partir de la crisis del capitalismo en los años 70, junto con las políticas de ampliación económica y desregulación, han ido transformando el modelo de crecimiento de las ciudades. El tipo de organización centralizada de la ciudad tradicional, devenida de la época industrial, se ve modificada por las transformaciones postindustriales de la economía mundial, logrando intensificar aun más la fase industrial y la terciarización del aparato productivo.

Estas transformaciones han desarrollado una nueva base económica mundial, en la que las actividades del aparato productivo conquistaron nuevos territorios y mercados globales, expandiéndose como una mancha urbana de aceite.

Se produce un cambio en la configuración urbana de la ciudad tradicional, caracterizada por un gradiente densimétrico en sentido centro-periferia, tanto en términos de población, como de actividad, empleo y su límite neto frente al entorno rural, hacia una forma más compleja, basada en un nuevo paradigma tecno-económico emergente, en el que la dispersión y la movilidad geográfica cumplen un papel importante (DE MATTOS, 2007).

Se cita a los Estados Unidos, como ejemplo más significativo en enfrentar estas transformaciones urbanas, y donde el suburbio presenta sus inicios más claros. Producto del desarrollo antes explicado, las clases sociales más acomodadas sentían el deseo de diferenciarse de las demás y aislarse del centro de la ciudad para asegurarse en los suburbios y disfrutar de la imagen del medio rural (MuMFord, 1963). Este modo de vida, que comienza en los EE. UU., se presenta como un modelo por seguir para fomentar una vida deseada y alternativa, alejada de los males de la ciudad industrial. El proceso de suburbanización más profundo se produce al finalizar la Segunda Guerra Mundial, y con la difusión del automóvil, se permitió una mayor expansión del espacio residencial.

La ciudad se expande junto con la sociedad misma, buscando el paisaje rural y trasformándolo en urbano debido a su crecimiento (Monclús, 1998b) ${ }^{2}$ Las ciudades comenzaron a crecer en número de población y gracias a las tecnologías de la comunicación dieron la posibilidad de buscar otras áreas urbanizables.

Se puede hacer una distinción un poco más detallada de los procesos de suburbanización de los países mediterráneos (Europa) y de los países anglosajones (Estados Unidos). La
2- El modelo anglosajón de expansión urbana relaciona los procesos de restructuración económica como causantes de la expansión dispersa de las ciudades, provocando así un esparcido urbano en todo el territorio. 
3- El urban sprawl representa indicios de un ideal americano, conformado por el individualismo, el acceso a la propiedad individual, la casa con jardin, el acceso al automóvil y la construcción de grandes extensiones de las redes de autopistas. ciudad mediterránea presentaba tradicionalmente una distinción entre la sociedad urbana y la sociedad rural, la cual se ha marcado en su territorio, llegando a diferenciarse bien los grupos sociales. Este proceso de expansión inicialmente se produce un poco más allá de las viejas murallas, colonizando al campo solo como espacio de transición y transformando el paisaje como áreas verdes para la ciudad. En cambio, los países anglosajones se expandían hacia el campo transformando su fisonomía rural en urbana. En el primer caso la suburbanización se produce sin dispersión urbana, siendo solo el jardín de la ciudad, y en el segundo caso la suburbanización se extiende como mancha de aceite, fundando la idea de ciudad jardín (Dematteis, 1996).

La suburbanización más conocida entonces se inició en los Estados Unidos, llegando a expandirse a otros países en vía de desarrollo, adoptando características residenciales en una primera instancia, y conformando espacios barriales de sectores socialmente homogéneos. La dispersión urbana que se manifestó fue la llamada urban sprawl. ${ }^{3}$

El proceso de suburbanización estuvo acompañado y promovido por la consolidación de los grupos familiares nucleares de los sectores medios, la evocación de la naturaleza, la vivienda relacionada con los espacios verdes y el predominio del transporte automotor, fomentado por la industria automotriz. Este proceso de suburbanización es una revolución urbana exteriorizada no solo con transformaciones físicas, sino más bien con transformaciones radicales de los estilos de vida urbanos. Establece espacios de transición entre la ciudad construida y el campo (HARLEY, 2008).

En America Latina el proceso de suburbanización tiene su inicio un poco más tardío, a mediados del siglo XX, cuando las suburbanizaciones provenían de las migraciones de población rural expulsada por la pobreza hacia las periferias de las ciudades. Esto se dio en la mayoría de los países, buscando oportunidades laborales y de hábitat, cimentándose así un proceso de asentamiento suburbano informal.

\section{IDEAS DE CIUDAD}

Dentro del estudio de los procesos de suburbanización se han fomentado diferentes ideas de ciudad, las cuales han configurado modelos particulares de implantación urbano-territorial por describir.

La idea de ciudad tradicional a lo largo de la historia de los asentamientos humanos era la de una ciudad central, cuyo modelo presentaba las características de compacidad y 
multifuncionalidad, fundamentadas en la continuidad, la cohesión, la mixtura de usos, la cercanía de las redes de la comunicación, la transmisión de la información y la interacción entre los elementos que la conformaban. Su estructura era la de una ciudad de esquema concéntrico, disminuyendo su densidad urbana desde el centro hacia la periferia.

La idea de ciudad dispersa es consecuencia de los procesos de suburbanización de los territorios de hoy. La urbanización de la ciudad industrial había traído aparejados los procesos de concentración de población e industrias, y su crecimiento urbano reflejaba esa condición. Luego en la ciudad postindustrial se generaron procesos contrarios de desconcentración urbana incitados por el desarrollo de las innovaciones tecnológicas y de las comunicaciones.

La urbanización posindustrial rompe con la división campo-ciudad, logrando revertir la situación generada por la industrialización, en la cual los habitantes se asentaban en las ciudades en busca de trabajo (desarrollo económico), y ahora en cambio los habitantes pueden habitar las periferias de las ciudades desarrollando actividades económicas, devenidas de la industrialización del campo y su terciarización (servicios). Los avances de la tecnología, las comunicaciones y la construcción de redes de movilidad dieron la posibilidad de expandir territorialmente y económicamente a los nuevos desarrollos económicos, gozando así de bajos niveles de rentas urbanas.

Las transformaciones económicas y tecnológicas han integrado funcional y físicamente el espacio urbano hasta tal punto que las actividades económicas junto con las nuevas formas de vida se han esparcido por todo el territorio (OrIOL NeL.LO, 1996).

La dispersión urbana de las ciudades tiene una íntima relación con el desarrollo de grandes infraestructuras viarias, los cambios en el estilo de vida y las nuevas pautas de consumo (De Mattos, 2002).

Esta nueva forma urbana dispersa se visualiza mediante una extendida descentralización de las grandes ciudades hacia áreas adyacentes o en la interconexión de pueblos preexistentes, cuyos territorios quedan integrados por las nuevas capacidades comunicacionales (CAStells, 2005).

En estas ideas de ciudades se puede observar también una importante asociación e inspiración en la utopía de recrear las ciudades o los suburbios jardines del siglo XIX, en 
la confección de áreas residenciales. Ideas que surgieron históricamente como posibles alternativas a las duras condiciones urbanas de las ciudades industriales y que se rematan hasta nuestros días.

\section{Ciudad Dispersa}

La ciudad dispersa es una confección de ciudad diferente de la ciudad tradicional, donde se promueve el crecimiento espacial polarizado y se presenta una íntima relación con las economías de aglomeración. Su urbanización se expande junto con las mejoras y los avances de las comunicaciones urbanas, urbanizando así los espacios rurales (DE MATTOs, 2001).

La idea de ciudad dispersa posee características predominantes en su modelo, como por ejemplo:

- la ocupación de suelo con baja densidad de uso;

- la baja densidad de población;

- los usos con zonificaciones únicas;

- la vivienda unifamiliar;

- la extensión de la trama urbana reticular;

- las redes de vinculación económica, social y cultural;

- la descentralización urbana, industrial y equipacional (monofuncionalidad);

- la evocación a la consolidación del grupo familiar;

- la dependencia de las redes de movilidad;

- el predominio del transporte automotor;

- la recreación de un estilo de vida más armónico en relación con la naturaleza;

- la representación de espacios barriales o de aldeas;

- las nuevas pautas de consumo.

Las áreas suburbanas de la ciudad dispersa presentan modalidades de organización territorial, composiciones sociales y características de desarrollo diferentes de las de la ciudad clásica (concentrada). Una posible explicación puede ser la transición de la etapa fordista a la etapa posfordista, caracterizada por las relaciones jerárquicas, que se relajan gracias a la flexibilidad de la organización productiva y del trabajo, la multiplicidad de conexiones horizontales y la aparición de identidades locales competitivas, enmarcadas hacia un contexto global (MoncLús, 1996c).

La ciudad dispersa, fomentada por la suburbanización, es el crecimiento de la ciudad en mancha de aceite, apareciendo en forma de periferias metropolitanas más o menos densas 
que en muchos casos se presentan sin continuidad física, como un crecimiento a saltos (Oriol Nel.lo, 1996).

La producción de un tejido urbano disperso es promovida mediante estructuras de asentamientos reticulares en forma de mallas, las cuales se extienden de forma ilimitada sobre el territorio urbano y donde en muchos casos crecen autónomos, llegando a conectarse luego con su futura extensión a la ciudad más próxima. Este crecimiento ha provocado varias consecuencias en las ciudades, cambiando su fisonomía urbana y su modo de crecimiento, funcionalización y organización clásica, descentralizando aspectos económicos, sociales y políticos; generando así segregación social, fragmentación urbana, desequilibrios económicos (ciudad dual) ${ }^{4}$, cambios en el paisaje urbano y nuevas centralidades.

Consecuentemente el proceso de desarrollo urbano de las ciudades ha comenzado a experimentar nuevos artefactos urbanos, como por ejemplo, conjuntos residenciales, complejos industriales, ciudades satélites y cambios urbanos significativos, como la transformación de ciudades pequeñas y medianas e incluso de núcleos rurales cercanos, en donde se convierten en unidades dependientes de la gran ciudad metropolitana. La revolución urbana global ha enfatizado estos cambios para poder desarrollarlos aun más en las ciudades de hoy.

La dispersión de la ciudad es la principal característica definidora de la nueva urbanización presente actualmente en las sociedades occidentales (BRYANT, 1982). Su crecimiento espacial es polarizado y fomentado por las economías de aglomeración. Desde el punto de vista espacial, en el fenómeno de la urbanización desconcentrada se conllevan flujos económicos y de población desde las áreas urbanas hacia las áreas rurales.

\section{Ciudad Jardín}

La ciudad jardín fue ideada para la transformación de las ciudades en vías de desarrollo, como modelo utópico, reuniendo las ventajas del campo con las de la ciudad, al margen del modelo capitalista y del socialismo de la época. El modelo howardiano, de principios del siglo XX, planteaba una ciudad como instrumento de reforma social, basada en conceptos de colectivismo y autogobierno, donde no existiera la separación de clases sociales y la vida se cimentara en comunidad (Peter Hall, 1996a). Se buscaba una relación más equilibrada entre el espacio residencial, el espacio productivo y la incorporación de la vida cotidiana a ciertos aspectos vinculados con el confort y con la dimensión simbólica de la vida en el campo (SZAJNBERG, 2005).
4- La ciudad dual, desde la visión sociológica del espacio urbano, señala la división fragmentada y bipolar de la estructura urbana dispersa y territorial de las ciudades, donde el espacio periférico se disputa entre las clases altas y las de bajos recursos. 
Las características de las ciudades jardines proyectadas por el modelo howardiano: - condiciones de habitabilidad saludables;

- viviendas unifamiliares con jardín;

- valorización del ambiente natural;

- espacios serenos y armónicos;

- ciudad autogestionada;

- superficie reducida a una población propuesta;

- valor paisajístico;

- interrelación social;

- visiones de comunidad.

El concepto de ciudad jardín fue cambiando con el tiempo hacia la derivación de ciudad satélite, donde ya no presentaba las condiciones de autogestión o autoeficiencia que planteaba Howard. Esta derivación fue la que tuvo más repercusión en la práctica urbanística de los primeros años del siglo XX, junto con la idea innovadora de descentralización en las ciudades, la cual creaba comunidades funcionales dentro de una misma ciudad (CóRDOBA, 2004).

La ciudad jardín entonces fue un modelo urbanístico teórico, ideado con desarrollo analítico y práctico, donde se buscó modificar la vida de las ciudades industriales hacia mejores condiciones de habitabilidad, llevando a muchos ejemplos a la concreción del modelo, y en muchos casos su modelo original se ha distorsionado para poder adaptarse a las diferentes evoluciones de las ciudades (PINTUs Gómez, 2009).

El suburbio jardín de Unwin y Parker, en cambio, fue planteado un poco más tarde en Hampstead (Inglaterra), ya no como ciudad jardín, sino como un asentamiento urbano dependiente de la ciudad central con características similares. Este modelo fue una alteración contraria al planteamiento de la ciudad jardín howardiana, el que pensaba a la ciudad como un modelo integral (político, social, cultural, económico, residencial y ambiental), proyectando barrios y suburbios aislados de la ciudad central, segregados social y económicamente, y presentando solo las características ambientales. Esto junto con las reformas de las vías de comunicación, tanto férrea como vial, impulsó el modelo hacia grupos sociales altos con la promoción de viviendas más confortables en relación con la naturaleza (PETER HALL, 1996b).

De esta manera, el suburbio jardín fue el que tuvo más difusión a la hora de pensar la extensión de la ciudad, extendiendo el área urbanizada hacia el área rural, transformando así su crecimiento tradicional. Ofrecía espacios residenciales de viviendas unifamiliares de 
planta baja o una planta, con jardines, uniformidad social y un uso del suelo estrictamente residencial alejado de la mixtura de usos de los centros urbanos. Su transformación terminó cimentando las bases de las ciudades dormitorios, gracias a su cercanía y su dependencia de la gran ciudad.

Estados Unidos presenta la influencia más notable sobre la transformación de los suburbios en las ciudades en vías de desarrollo. Inspirados en la creación de barrios jardines, planificaron la extensión y la posibilidad de nuevas áreas para la residencia ciudadana. La construcción de cinturones verdes, calles, avenidas zonificadas y un diseño inspirado en la naturaleza, la casa individual y una vida socialmente homogénea fueron las premisas para su construcción.

El modelo del suburbio norteamericano presentaba una solución física y social en las ciudades industriales del siglo XX, devenida de las componentes socioeconómicas, las cuales exteriorizan las nuevas condiciones de vida urbana.

\section{EL PROCESO DE SUBURBANIZACIÓN DEL CORDÓN OESTE METROPOLITANO DE ROSARIO}

\section{La periferia de Rosario}

La ciudad de Rosario ha transitado un proceso de suburbanización sometido a diversos cambios y funciones de las áreas metropolitanas. Estos cambios urbanos fueron subordinados a diferentes espacios-temporales, uno de ellos fue entre los años 1870-1930, cuando se consolidaron los centros fundacionales de los poblados nacidos en torno de las estaciones ferroviarias. Proceso en el cual existía un estado liberal y una política agroexportadora que recibía importantes flujos migratorios europeos. Este particular proceso se mantuvo en los principios de la etapa fordista y se ha caracterizado por contener cambios socioeconómicos significativos, como la apertura de los puertos, la inserción del ferrocarril y la fundación de colonias agrícolas.

Otro reconocido espacio temporal se dio entre los años 1940-1960, dentro de un estado social desarrollista y surgido del proceso de industrialización sustitutivo de importaciones, el cual caracterizó importantes fuentes migratorias internas. Este proceso se acentuó en el cambio de la etapa fordista a la etapa posfordista, descentralizando las actividades productivas del sector secundario y dando como resultado la expansión de la periferia de Rosario. Se consolidaron así las áreas más externas de la ciudad produciendo una densificación del área central. 
Como último espacio se puede reconocer la etapa comprendida entre los años 1960-1980, sumergida en un Estado neoliberal y con orientaciones al mercado externo, donde se iniciaba un desmantelamiento gradual del desarrollo antes explicado. Este proceso generó una disminución de las migraciones y de las políticas públicas a nivel urbano, y en él la privatización del espacio y de los bienes públicos y la influencia del mercado comenzaron a cobrar importancia.

A partir de los años 80 y 90, se exhibían nuevos ámbitos de comercialización de bienes y servicios terciarios, por lo cual la ciudad de Rosario presentó una serie de transformaciones urbanas que articulan la ciudad con el resto del área metropolitana. Transformaciones como el saneamiento de la cuenca inundable del arroyo Ludueña, la formalización de parques regionales, la localización de grandes centros comerciales, la concentración de equipamientos recreativos y deportivos, etc., han modificado el valor antepuesto de la periferia rosarina.

Estos cambios expresados en el área metropolitana de la ciudad de Rosario hacen alusión a la referencia conceptual que hacen los autores De Mattos y Bryant, donde exhiben a la suburbanización como producto de las economías de aglomeración, de la metropolización expandida, de las mejoras y avances comunicacionales e infraestructurales, y de los nuevos artefactos urbanos.

La periferia rosarina se caracterizaba entonces por contener varias situaciones representativas. Una de ellas son los loteos con parcelas de dimensiones mínimas para sectores de bajos ingresos, que ocupaban lentamente el espacio mediante operaciones de autoconstrucción. Estos loteos se levantaban en áreas con escasos servicios infraestructurales y materialización precaria. Otra situación eran los conjuntos de habitacionales formulados por las actuaciones públicas, que proyectaban nuevas viviendas, con la incorporación de equipamientos colectivos. Y por último la existencia de unos pocos asentamientos irregulares y la inserción de grandes establecimientos productivos y de depósitos.

La ciudad de Rosario solo contaba con un área residencial periférica de sectores de altos ingresos, como así también de ingresos medios-altos (Fisherton), situada en el sector oeste de la ciudad. Esta área residencial es de antigua formación, que surgió originalmente como un poblado autónomo, y el crecimiento de la ciudad lo absorbió con el tiempo.

El barrio jardín de la localidad de Rosario (Fisherton) originalmente presentaba una historia ligada a las vías del Ferrocarril Central Argentino, que conectaba Rosario-Córdoba. El 
barrio fue destinado a ser habitado por el personal jerárquico de la empresa, y su particular territorio exhibía grandes extensiones rurales y una rica forestación, asentándose así una urbanización alrededor de la estación ferrocarril, que posteriormente desarrolló su extensión de forma longitudinal y siguiendo las trazas ferroviarias. De igual modo, tuvo gran influencia la incidencia de las vías de comunicación oeste de la ciudad, que conectaban el barrio jardín con el resto de la ciudad (por ejemplo, la calle Eva Perón, ex Córdoba).

Este pequeño barrio, en sus características, presentaba indicios de los suburbios jardines siglo XIX, siendo de esta manera un barrio socialmente homogéneo, de baja densidad, con casas unifamiliares y grandes extensiones de verde. Presentaba un área netamente residencial, contando solo con un área comercial y de abastecimiento por la conexión de la calle Eva Perón. En términos urbanísticos se puede decir que este particular barrio significó un ideal urbano de grandes residencias de poder adquisitivo para la ciudad de Rosario y la región.

La ciudad de Rosario y su área metropolitana han sido tradicionalmente una zona de importante presencia industrial y comercial en la región. A mediados de los años 90, la ciudad presentó un cambio significativo con la construcción de autopistas, puentes y nuevas vías de acceso, las cuales han jerarquizado determinadas zonas urbanas que anteriormente eran de uso portuario. Con el correr de los años ha decaído su actividad portuaria y la producción de diferentes industrias debido a los profundos cambios económicos de nuestro país, que provocaron la destrucción de puestos de trabajo y cierre de muchas empresas. Esto desató el desarrollo de la actividad terciaria (comercios y servicios) como manera de escape a la crisis.

Los cambios en la modernización de las infraestructuras económicas, el desarrollo de las infraestructuras de soporte, la reconversión industrial y de servicios, las nuevas formas de urbanización y un marcado desequilibrio social fueron los factores clave en la transformación de la periferia rosarina.

La influencia de importantes obras infraestructurales que emplazan a Rosario con respecto a la región, como el puente Rosario-Victoria, la autopista Rosario-Córdoba, el proyecto de la Hidrovía y del nuevo puerto dieron lugar a nuevas expectativas de desarrollo urbano.

Uno de los principales cambios en la periferia urbana se observó en el tramo sur, la mayor cantidad de operaciones de vivienda publica y el incremento de los asentamientos irregula- 
5- Esta visión especulativa inmobiliaria se basa en la disposición y en la venta de terrenos relativamente baratos, mayormente sin infraestructura pública, para la construcción de segundas viviendas o viviendas de fin de semana para la región. res; y otro en el tramo noroeste y oeste, la localización de grandes centros comerciales y recreativos, situados en los nudos de articulación de la ciudad con el territorio más próximo, junto con intervenciones residenciales de carácter privado. De igual modo, el tramo oeste de la ciudad de Rosario, en materia residencial y de servicios complementarios, comenzó a concentrar importantes intervenciones residenciales, incentivadas por actores privados capaces de observar el espacio periférico como un espacio de nuevos emprendimientos urbanos (visión especulativa inmobiliaria). ${ }^{5}$

Es así como los nuevos loteos periféricos del sector oeste constituyeron la expansión de uno de los barrios jardines más tradicionales de la ciudad (Fisherton). Se pueden citar como ejemplos la urbanización de Aldea y la del barrio Carlos Pellegrini (1994), que fue pionero en su ejecución y exteriorizó la nueva imagen de los barrios residenciales cerrados en la ciudad y en la región.

Las razones de la radicación de residencias en la periferia de la ciudad se facilita por la inexistencia de parcelas vacantes y el alto valor de los inmuebles en la urbanización tradicional (MATEOS, 2001).

Se inició entonces la construcción de nuevos tipos de urbanizaciones residenciales, como los loteos de cierta calidad con servicios comunes, parcelas de mayores dimensiones y barrios cerrados. También en correlación se proyectó la construcción de clubes privados de gran dimensión.

Los cambios en los estilos de vida de los sectores de ingresos medios, medio-altos y altos de la población fomentaban nuevas demandas específicas de seguridad y de modelos de núcleos residenciales urbanos. Los cambios en las pautas de consumo, los recientes desarrollos de las comunicaciones y las proyecciones inmobiliarias han demandado nuevas tendencias urbanas en la construcción de la vivienda permanente. Estas nuevas tendencias incluyen la búsqueda de mejores condiciones de calidad de vida ciudadana, la elección de una vivienda unifamiliar y una relación más directa con la naturaleza.

Dentro de esta misma lógica, como se expuso anteriormente por HarveY y Monclús, los procesos de suburbanización estuvieron promovidos también por las transformaciones radicales en los estilos de vida urbanos, expandiéndose de este modo junto con la sociedad misma. De igual modo se refleja también lo expuesto por De MATTos, cuando hace alusión a las nuevas pautas de consumo. 


\section{El Cordón Oeste Metropolitano}

La manifestación urbanística del sector oeste de la ciudad, en la construcción de nuevas áreas residenciales, comenzó a repercutir en ciudades vecinas como Funes y Roldán, logrando cimentar las bases del cordón oeste metropolitano de Rosario. Las ciudades de Funes y Roldán comenzaron desde los años 60 a posicionarse como centros urbanos para la radicación de viviendas de fin de semana para la población rosarina y de la región. Se comenzaba a afirmar la idea de tener una casa de reuniones familiares para los fines de semana con grandes espacios verdes y recreativos.

Se presenta el sistema de comunicación oeste del ferrocarril Rosario-Córdoba, a modo de visualizar el recorrido ferroviario que atraviesa ciudades intermedias a su paso, como San José de Ávila (Funes), Colonia Bernstadt (Roldán) y el barrio Fisherton (Rosario) (ver figura N. ${ }^{\circ}$ ).

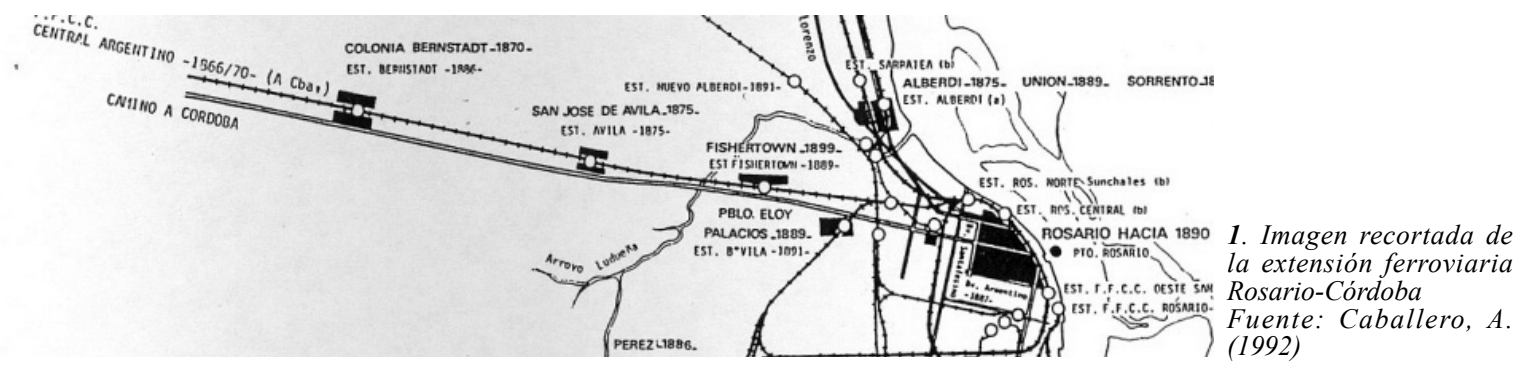

Se puede decir, entonces, que el tramo oeste metropolitano de la ciudad de Rosario presentaba las mayores transformaciones urbanas en materia de vivienda y servicios terciarios, capaces de abastecer las futuras demandas de los residentes rosarinos. Las nuevas urbanizaciones locales fueron proyectadas por diferentes actores privados, quienes fueron capaces de ver en la transformación de las tierras rurales o suburbanas un incremento en su valor económico.

El cordón oeste metropolitano de Rosario se presenta como un área de desarrollo urbano intenso, vinculado con la producción de nuevos modelos de residencias unifamiliares. Este sector, que comienza con pequeñas intervenciones inmobiliarias, de venta de loteos de fines de semana para la recreación fin semanal de los residentes de Rosario a principios 


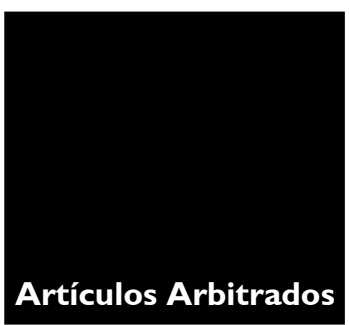

Alejandra M. J. Parussini

de los años 60, se consolida a través del tiempo, y en los años 90 es un área preferencial a la hora de buscar una nueva residencia, con grandes espacios verdes, aire puro y una vida más en contacto con la naturaleza.

De igual modo se exhibe la figura 2, en la cual se pone de manifiesto la relación física y funcional que presentan las localidades del cordón oeste metropolitano de Rosario con la ciudad de Rosario, visualizando de esta manera las vías de comunicación territorial, los límites distritales y las fisonomías urbanas.

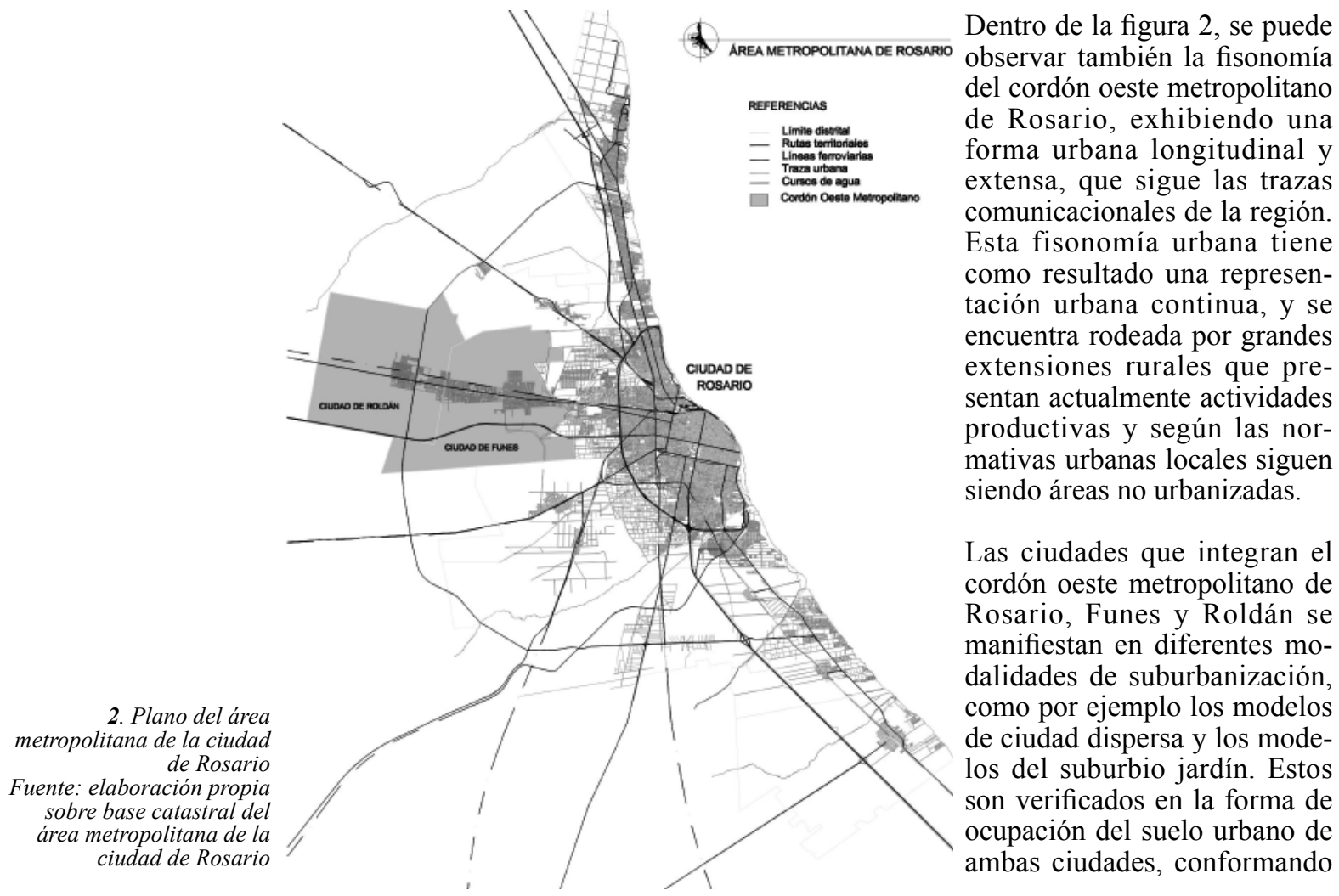


así un territorio muy extenso con bajas densidades de población urbana. De la misma manera sus particularidades paisajísticas y ambientales recrean un ambiente privilegiado para la recreación y la vida más en contacto con el aire libre.

De esta manera, las ciudades del cordón oeste metropolitano representan un modelo ideal que seguir para la nueva residencia y para la especulación inmobiliaria tanto a nivel local como regional.

\section{Origen Urbano-Territorial}

Para poder comprender el crecimiento y las transformaciones urbanas, se presenta a continuación un breve resumen del origen del cordón oeste metropolitano de Rosario, desarrollando las particularidades de sus dos localidades por separado.

La localidad de Funes presenta una extensión urbana ortogonal y simétrica en relación con su eje fundacional, que comenzó a extenderse hacia el sur con la pavimentación de la ruta nacional 9, coincidiendo con el ferrocarril en su estructura longitudinal. La urbanización se desarrolló entonces con una clara tensión lineal este-oeste, en el mismo sentido de las trazas viales y ferroviarias, que componen los hechos primarios de la ciudad. Estas urbanizaciones constituyeron un continuo urbano que comienza en el arroyo Ludueña (parcialmente límite del municipio Rosario) y se extiende hacia el oeste llegando hasta la localidad de Roldán, dando como resultado un área urbanizada muy extensa, con baja densidad y con bajos niveles de dotación infraestructural. De igual modo y más recientemente, dentro de su extensión hacia el sur, tuvo mucha influencia otro componente vial, la proyección del tramo (avenida Circunvalación-Carcarañá) de la autopista Rosario-Córdoba, que actualmente se extiende hasta la ciudad de Córdoba.

La localidad de Roldán presenta una extensión urbana de trazado ortogonal y simétrico a su eje fundacional, originado también por las líneas del ferrocarril, siendo estos hechos primarios de la ciudad. La extensión se inició hacia el norte respetando su trazado original, y su extensión hacia el sur, en cambio, se proyectó de manera semicircular alterando su fisonomía original. Su evolución urbana se produce sobre la ruta nacional 9, llegando hasta el límite este de la localidad con la localidad de Funes, el cual presenta un corte urbano causado por el cruce perpendicular de la ruta nacional AO12. Esta extensión ha confeccionado un continuo urbano entre ambas localidades; luego un poco más tardíamente y hacia el sector norte, se produce la urbanización por la ruta AO12. La urbanización resultante era muy extensa, con baja densidad y también con bajos niveles de dotación infraestructural. 
El crecimiento general del territorio se originó de una manera discontinua, siendo un modo de crecimiento caracterizable como la expansión a saltos, que se desarrolla sin continuidad alguna con los cascos fundacionales. Esta manera de crecimiento desordenado del territorio, producto de las ventas inmobiliarias de nuevos loteos para el sector, dio como resultado un área de poca regulación y planificación urbana, logrando generar grandes aéreas intersticiales de poco completamiento urbano (BRAGOS, 2003).

Es así como los agentes inmobiliarios o los diferentes actores privados han observado de manera especulativa esta situación, para poder proyectar y promocionar nuevas áreas urbanizables y completar los grandes intersticios urbanos. La motivación de generar nuevos espacios residenciales estaba vinculada con la oferta de viviendas de fin de semana para solventar las demandas rosarinas, las cuales un período más tarde se volcaron a promocionar viviendas para residentes definitivos.

\section{Crecimiento demográfico}

El proceso de transformación del cordón oeste metropolitano de Rosario se puede demostrar mediante el crecimiento demográfico de ambas localidades. Se comprueban cuantitativamente los incrementos poblacionales registrados en los últimos censos, detallando y particularizando sus crecimientos demográficos, sus crecimientos migratorios, sus superficies territoriales y sus cálculos resultantes de densidad poblacional (ver cuadro 1).

Cuadro $\mathrm{N}^{\mathrm{o}} 1$. Población, crecimiento, superficie y densidad del cordón oeste metropolitano de Rosario

\begin{tabular}{|l|l|l|l|l|l|l|}
\hline Localidad & $\begin{array}{l}\text { Población } \\
\text { 1991 }\end{array}$ & $\begin{array}{l}\text { Población } \\
\text { 200I }\end{array}$ & $\begin{array}{l}\text { Crecimiento } \\
\text { demográfico }\end{array}$ & $\begin{array}{l}\text { Creci- } \\
\text { miento } \\
\text { migratorio }\end{array}$ & Superficie & $\begin{array}{l}\text { Densidad } \\
\text { de pobla- } \\
\text { ción }\end{array}$ \\
\hline Funes & 8.270 hab. & 14.750 hab. & $64,8 \%$ & $26,7 \%$ & $100 \mathrm{~km} 2$ & $\begin{array}{l}\mathrm{I} \% 7,50 \\
\text { hab/km2 }\end{array}$ \\
\hline Roldán & 9.382 hab. & II.468 hab. & $22,2 \%$ & $12,6 \%$ & $114 \mathrm{~km} 2$ & $\begin{array}{l}\mathrm{I} / \mathrm{km}, 6 \mathrm{I} \\
\mathrm{hab} / \mathrm{km} 2\end{array}$ \\
\hline
\end{tabular}

Fuente: elaboración propia con datos del Censo Nacional de Población, Hogares y Vivienda, INDEC periodo 1991-2001

Este cuadro nos representa el aumento poblacional registrado en 10 años consecutivos del período 1991-2001, presentando un elevado incremento demográfico en ambas localidades. 
La localidad de Funes se encuentra más afectada hasta el momento que la localidad de Roldán, teniendo un $64,8 \%$ a diferencia de un $22,2 \%$ de crecimiento demográfico. Pero llegando hasta nuestros días no podemos medir el incremento final de la transformación urbana local, ya que no contamos con los últimos registros censales del período 2001-2011.

Si bien este cuadro representa de modo cuantitativo el aumento de población de ambas localidades según los censos registrados, no manifiesta el incremento fin semanal que representa en el cordón oeste metropolitano de Rosario hacia la región. Este incremento poblacional se ve afectado significativamente casi en un $30 \%$ los fines de semana, provocado por la llegada de visitantes a las viviendas de segundas residencias, y de igual modo tampoco representa el aumento duplicativo de población que existe en los meses de veraneo en la región. Tanto en los fines de semana como la época veraniega, los destinos de Funes y Roldán se tornaron electivos a la hora de optar por un lugar de esparcimiento y de recreación familiar.
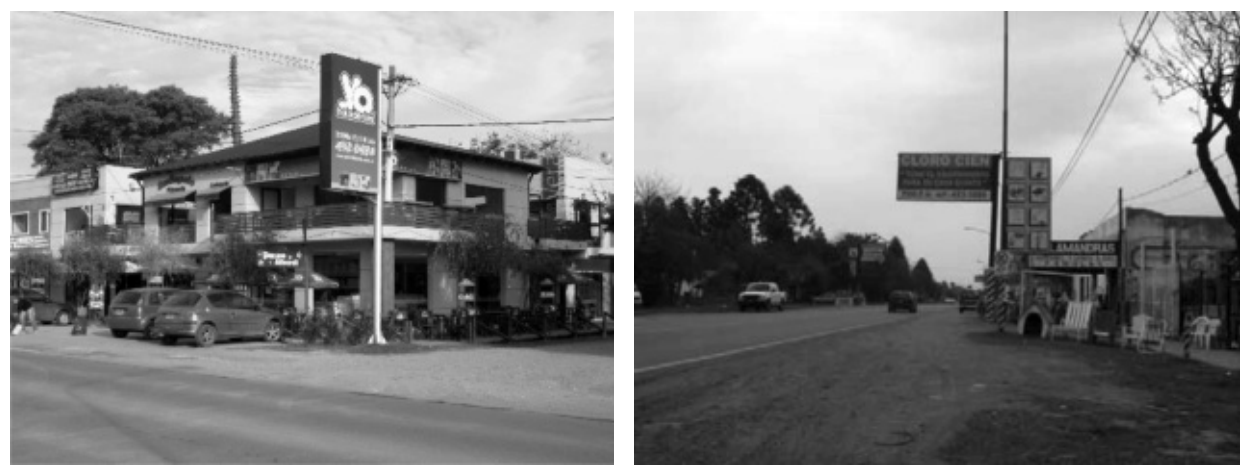

3 y 4. Imágenes de comercios sobre la ruta nacional 9 a la altura de la localidad de Funes.

Fuente: http://www.google. com.ar/images? $q=$ imagene $s+$ de + comercios + por + ruta $+9+$ funes + santa $+f e$

Las localidades de Funes y Roldán, estimuladas por este incremento poblacional, comenzaron también a incrementar las actividades comerciales y de servicios, las cuales se vieron manifestadas para el abastecimiento de las necesidades ocasionales y las permanentes. Este incremento se ve reflejado en la incorporación de nuevos negocios a lo largo de las rutas comunicacionales (ver figuras 3 y 4 ). De igual modo su equipamiento comunitario y su potencial desarrollo local se encuentran en constante evolución urbana. 


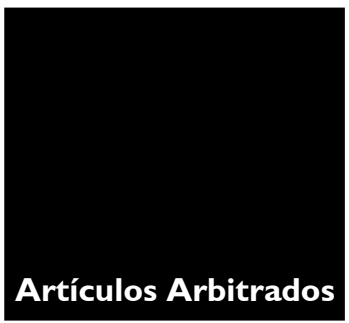

Alejandra M. J. Parussini

Particularidades paisajísticas, ambientales y nuevas modalidades de residencia

Las particularidades paisajísticas y ambientales del territorio generaron un atractivo significativo hacia ambas localidades, aportando un valor agregado al modo de urbanización disperso en el cual se desarrollan. Esta modalidad se ve reflejada en el modelo de dispersión urbana antes explicada, el urban sprawl, representando la idea de una vida nueva y alejada de los centros urbanos. Es así como comenzó a existir en el imaginario ideal de los ciudadanos de la ciudad de Rosario la idea de poder vivir en un área diferente, con grandes espacios libres y la posibilidad de poseer una vivienda unifamiliar nueva y de gozar de una relación más directa con la naturaleza.

Las localidades del cordón oeste metropolitano de Rosario exhiben características paisajísticas y ambientales visualizadas en las figuras 5 y 6 , como por ejemplo:

- la presencia de grandes espacios verdes;

- la presencia de asoleamiento y aire puro;

- un paisaje forestal con variedades de especies;

- la mayoría de las calles sin asfaltar, con un pequeño estabilizado o simplemente de tierra;

- viviendas unifamiliares;

- un mayor contacto con la naturaleza;

- grandes veredas y retiros de las edificaciones.

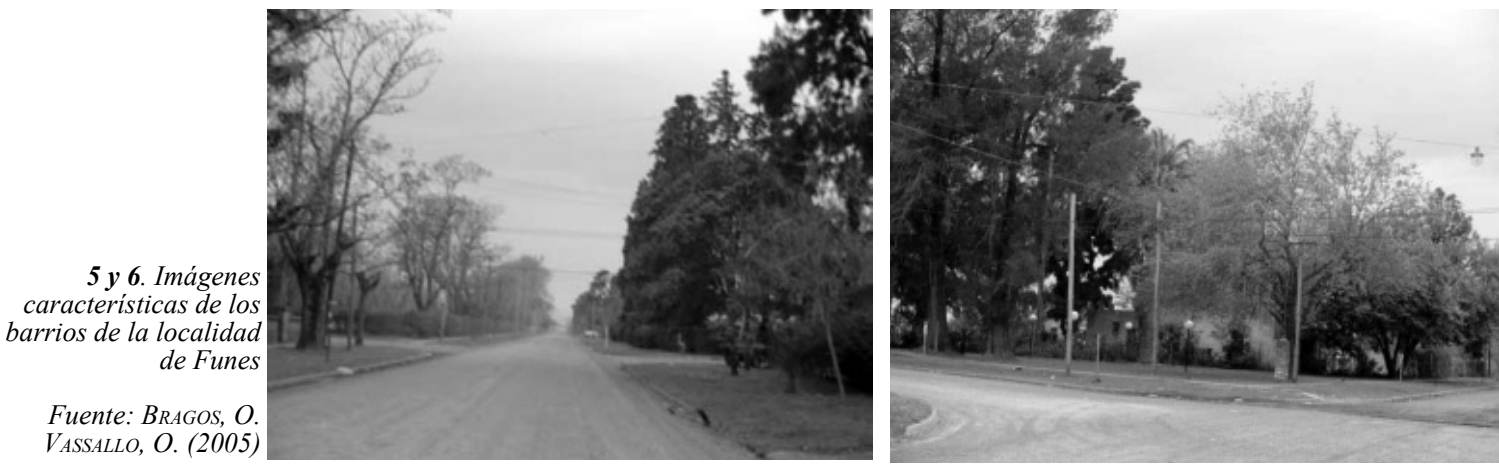

Hasta acá podemos distinguir que las transformaciones urbano-territoriales del cordón oeste metropolitano de Rosario se ven manifestadas en las particularidades antes explicadas de los modelos de ciudad dispersa y del suburbio jardín. Recordemos que la ciudad dispersa 
se manifestaba por contener situaciones de crecimiento extensivo, logrando conquistar nuevos territorios circundantes, y con respecto a los suburbios jardines existe una relación directa con la forma original del territorio y sus características paisajísticas, que logran particularizar el cordón oeste metropolitano como un referente residencial suburbano.

Estas transformaciones urbanas, además de poseer características de los modelos de ciudad dispersa y de suburbio jardín, también representan una modalidad nueva de urbanización en el territorio, llamada urbanización privada, como por ejemplo los barrios cerrados o los clubes de campo. Las nuevas modalidades de urbanización incorporan características diferentes para las localidades, como la construcción de equipamientos comunitarios, una seguridad interna y la condición de ser un territorio privado. Se observa de esta manera en las figuras 7 y 8 una visión de transformación del ambiente original de la localidad hacia un nuevo tipo de construcción más globalizada, determinada por los tiempos de hoy.
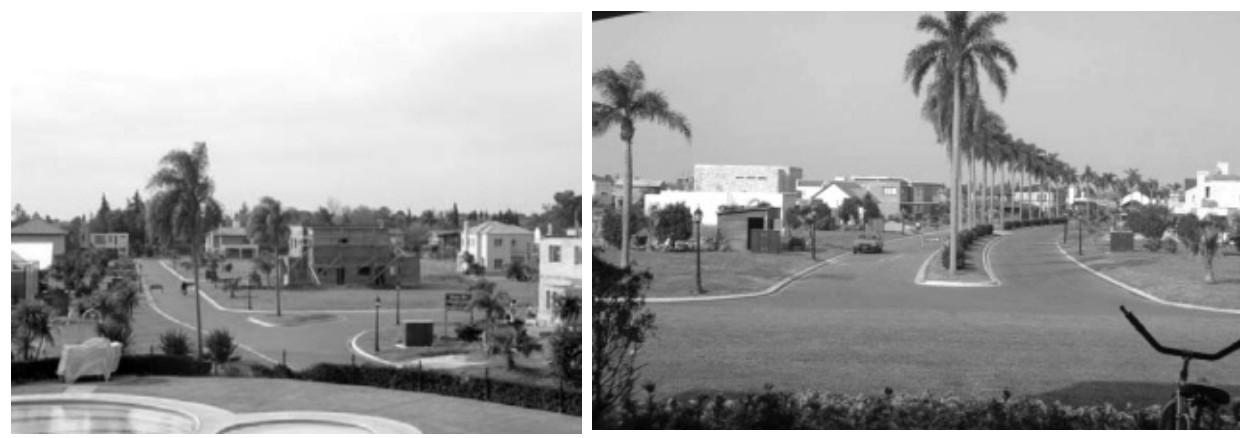

$7 y$ 8. Imágenes de uno de los barrios de la cadena Funes Hills. Barrios cerrados Fuente: Bragos, $O$ Vassallo, O. (2005)

Se registran hasta el momento más de 24 barrios proyectados y en ejecución en la localidad de Funes y más de 17 barrios proyectados y en ejecución en la localidad de Roldán, que configuran las nuevas urbanizaciones del cordón oeste metropolitano de Rosario. Muchas de estas urbanizaciones se diferencian en su estructura morfológica por ser de carácter abierto, privadas o cerradas, y de completamientos urbanos (loteos más pequeños).

\section{A MODO DE REFLEXIÓN}

Podemos sintetizar que el estudio del caso del cordón oeste metropolitano de Rosario se vio afectado por contener diferentes situaciones urbanas, tanto de completamiento como en la construcción de nuevos loteos en el territorio. Esta transformación comprende tanto a las 
ciudades de Funes y de Roldan, como también originalmente al sector oeste de la ciudad de Rosario (barrio Fisherton). El resultado fue la prolongación de sus plantas urbanas que, junto con las nuevas urbanizaciones de carácter privado, se extendieron hasta los límites distritales, conformando así una masa urbana de continuo urbano disperso.

Dentro de esta misma lógica se comprueba la valoración conceptual de CASTELLS, en cuanto al resultado de esta nueva forma urbana, que se visualiza mediante una extendida descentralización de las grandes ciudades hacia áreas adyacentes o en la interconexión de pueblos preexistentes, cuyos territorios quedan integrados por las nuevas capacidades comunicacionales.

Es así como la ciudad de Rosario y su región han tomado la influencia de estas transformaciones urbanas, cambiando las configuraciones y morfologías de las ciudades vecinas, modificando o potenciando sus visiones de ciudad, con la finalidad de poder guiar su crecimiento urbano futuro e integrarse a las posibles demandas regionales. En este trabajo se intentó dar a conocer las primeras pautas de estudio, evocando posibles reminiscencias pasadas en correlación con los cambios actuales, relacionando de esta manera la construcción de nuevos espacios de vida suburbanos, conformando las mismas lógicas e ideas de ciudad antes desarrolladas.

\section{BIBLIOGRAFÍA}

BRAGOS, O. (1991). "La formación de la periferia en un conglomerado urbano. El caso de la comuna de Roldán (Conglomerado del Gran Rosario)”. CURDIUR, Centro Universitario Rosario de Investigaciones Urbanas y Regionales.

BRAGOS, O., MATEOS, A., PONTONI, S. y VASSAllo, O. (2005). "La capacidad de gestión territorial en municipios pequeños y medianos del área metropolitana de Rosario: los casos de Funes y Pérez". Presentado en III Seminario CIFOT. Publicado en CD, Mendoza.

CABALLERO, A. (1992) Extensión Metropolitana de Rosario. Proceso de formación urbano - territorial y dinámica de transformación, Rosario.

DEMATTEIS, G. (1998) Suburbanización y Periurbanización. Ciudades Anglosajonas y Ciudades Latinas. En: MONCLÚS, Javier (Ed.), Op. cit., Barcelona. 
DEMATTEIS, G., y GOVERNA (2001). "Urbanización y Gobernanza. Las nuevas multi-centralidades urbanas".

DE MATTOS, C. A. (2001). "Metropolización y Suburbanización". EURE N. o 080, mayo, Vol. XXXVIII. Pontífica Universidad católica de Chile, Santiago.

FLORIANI, H. y MARTíNEZ de S. V., I. (2000). "Un relevamiento de las principales transformaciones en la estructura y la morfología Urbano-Territorial de Rosario y su Área Metropolitana". Universidad Nacional de rosario, Concejo Nacional de Investigadores Científicas y Técnicas, Rosario.

HALL, VAN DEN BERG y KLAASSEN (1983). "La Teoría de la Evolución de las Ciudades". Editorial, Van Den Berg, L. Bruns, L.S. Kaassen. Alderhor, Gower.

LEFEBVRE, H. (1971) De lo rural a lo urbano. Ediciones Península, Barcelona.

LEFEBVRE, H. (1970) La Revolución Urbana. Editorial Alianza, Madrid.

MATEOS, A. (1999). "Transformaciones recientes en la Periferia de Rosario. Identificación y Caracterización de Procesos y Tendencias". CURDIUR, Centro Universitario Rosario de Investigaciones Urbanas y Regionales.

MONCLÚS, J. (1998) La Ciudad Dispersa. Suburbanización y nuevas periferias. Centro de Cultura Contemporánea. Editorial Monclús, Barcelona.

ORIOL, Nel.lo (1996). "Los confines de la ciudad sin confines. Estructura urbana y límites administrativos en la ciudad difusa". Barcelona.

PINTUS GÓMEZ, A. (2009). "Suburbio jardín y pintoresquismo. Una mirada historiográfica". Universidad nacional de Colombia, Colombia.

RUEDA, S. (1998). "La Ciudad Compacta y Diversa frente a la conurbación difusa". Madrid.

SZAJNBERG, D. (2005). La Suburbanización. Partidarios y detractores del crecimiento urbano por derrame. Editorial FADU, Buenos Aires.

VELASQUEZ, I. (2003). "Ciudad Difusa, Urbanización discontinua o desurbanización creciente. La expansión de la ciudad". Revista EL Ecologista N. ${ }^{\circ}$ 34, Madrid. 



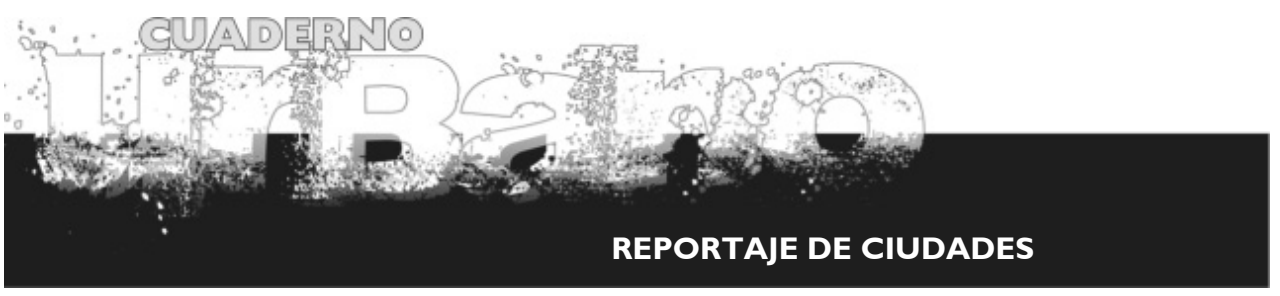

